\title{
Bone marrow oedema-type signal in the proximal phalanx of Thoroughbred racehorses
}

\author{
Fumiaki MIZOBE ${ }^{1) *}$, Motoi NOMURA ${ }^{2)}$, Takanori UENO ${ }^{3)}$ and \\ Kazutaka YAMADA ${ }^{4)}$ \\ ${ }^{1)}$ Racehorse Hospital, Miho Training Center, Japan Racing Association, Ibaraki 300-0493, Japan \\ ${ }^{2)}$ Racehorse Hospital, Ritto Training Center, Japan Racing Association, Shiga 520-3085, Japan \\ ${ }^{3)}$ Equine Research Institute, Japan Racing Association, Tochigi 329-0412, Japan \\ 4)Laboratory of Veterinary Radiology, School of Veterinary Medicine, Azabu University, \\ Kanagawa 252-5201, Japan
}

J. Vet. Med. Sci.

81(4): 593-597, 2019

doi: 10.1292/jvms.18-0530

Received: 3 September 2018 Accepted: 21 February 2019 Published online in J-STAGE: 4 March 2019
ABSTRACT. This study focused on 8 Thoroughbred racehorses showing bone marrow oedema-type signal in the proximal sagittal groove of the proximal phalanx, with the aim of understanding its clinical significance. Standing magnetic resonance imaging played an important role in assessing osseous abnormalities that were not radiographically identifiable. Further, a histopathological result from one of the cases showed there was oedema surrounding adipose tissues with increase in density of trabecular scaffolding. This may indicate presence of osseous injury within the area of decreased elasticity due to subchondral bone modeling. This study suggests that detection of osseous abnormality based on bone marrow oedema-type signal, and application of appropriate care following injury would contribute to prevent deterioration of stress-related fractures of the proximal phalanx.

KEY WORDS: bone marrow oedema, magnetic resonance imaging, proximal phalanx, Thoroughbred

Bone marrow oedema (BMO) is a general term introduced and used to describe the replacement of bone marrow fat by material containing $\mathrm{H}^{+}$ions, in the form of water [11]. Fluid based changes within the bone is characterized by intraosseous short tau inversion recovery (STIR) and T2* (sequence using gradient echoes and relatively long echo time) hyperintensity. These signal changes can be seen as a result of various pathologies including articular fracture, trabecular microfracture, osseous cyst, osteonecrosis and infections. Therefore, some argue that bone marrow lesions may be more appropriate terms, particularly when referring to the distal sesamoid bone [9]. This is in agreement with the recent literature in the human field [3]. Others have proposed to use 'high fluid signal' to describe the feature associated with replacement of fat by water [8]. In the present study the term BMO-'type' (BMO-t) is chosen in reference to a study of Thoroughbred fetlock using standing magnetic resonance imaging (sMRI) by Powell [12].

In equine diagnostic imaging, BMO-t signal has been reported in the majority of the osseous structures of the distal limb, such as middle phalanx, distal sesamoid bone, proximal and distal third metacarpus/metatarsus (MC3/MT3) [5, 14, 19]. The finding of BMO-t signal in the proximal phalanx (P1) was first described in 2010 from the cases in which short proximal sagittal groove fractures were suspected [15]. As proposed in the study, there is a growing recognition that stress-related pathology can be associated with the development of sagittal P1 fracture. More recently, this theory has been supported by a study using microcomputed tomography, which indicated that chronic exposure to stress could lead to excessive or inappropriate modeling or remodeling of the subchondral bone (SCB), characterized by variance in SCB volumetric mineral density observed in the contralateral limbs of P1 fractured cases [10]. These evidence may imply that avoidance of the progression to complete fracture could be possible by awareness of the clinical features and utilization of appropriate imaging modalities, such as sMRI. From this back ground, the current study focused on clinical cases showing the BMO-t signal pattern with the aim of further understanding alterations in the P1 sagittal groove of Thoroughbred racehorses.

Case descriptions of 8 Thoroughbred racehorses are summarized in Table 1. In essence, lameness was present in all cases on admission. Case 1, 2, 3, 5 and 7 had effusion in the metacarpo-/metatarsophalangeal joint of the lame limb. Pain response was elicited by palpation over the proximal dorsal aspect of the P1 in all cases. Case 2 underwent diagnostic anesthesia of the palmar and metacarpal nerves performed at the level of the fetlock joint (low 4-point) using 2\% mepivacaine (Mepivacaine, AstraZeneca

*Correspondence to: Mizobe, F.: Fumiaki_Mizobe@jra.go.jp

O2019 The Japanese Society of Veterinary Science

This is an open-access article distributed under the terms of the Creative Commons Attribution Non-Commercial No Derivatives (by-nc-nd) License. (CC-BY-NC-ND 4.0: https://creativecommons.org/licenses/by-nc-nd/4.0/) 
Table 1. Case description

\begin{tabular}{|c|c|c|c|c|c|c|c|}
\hline \multirow[b]{2}{*}{ Case } & \multicolumn{3}{|c|}{ Clinical findings on admission } & \multirow[b]{2}{*}{ Radiography } & \multirow[b]{2}{*}{ Standing MRI } & \multirow{2}{*}{$\begin{array}{l}\text { Period from } \\
\text { admission to first } \\
\text { race return }\end{array}$} & \multirow{2}{*}{$\begin{array}{c}\text { Follow-up period } \\
\begin{array}{c}\text { Number of races } \\
\text { post-injury }\end{array}\end{array}$} \\
\hline & Lameness $^{\text {a) }}$ & Fetlock joint & $\begin{array}{c}\text { Response to } \\
\text { digital pressure }\end{array}$ & & & & \\
\hline $\begin{array}{c}1 \\
(3 y o, \text { male })\end{array}$ & Grade 1 & Distention & Positive & Unremarkable & BMO-t ${ }^{b)}$ & 130 days & $\begin{array}{c}13 \text { months } \\
10\end{array}$ \\
\hline $\begin{array}{c}2 \\
\text { (3yo, female) }\end{array}$ & Grade 1 & Distention & Positive & Unremarkable & BMO-t $\mathrm{t}^{\mathrm{b}}$ & 133 days & $\begin{array}{c}24 \text { months } \\
32 \\
\end{array}$ \\
\hline $\begin{array}{c}3 \\
(3 y o, \text { female }) \\
\end{array}$ & Grade 2 & Distention & Positive & Unremarkable & BMO-t ${ }^{b)}$ & 180 days & $\begin{array}{c}7 \text { months } \\
1\end{array}$ \\
\hline $\begin{array}{c}4 \\
(2 \mathrm{yo}, \text { female }) \\
\end{array}$ & Grade 2 & No distention & Positive & Unremarkable & BMO-t ${ }^{b)}$ & 242 days & $\begin{array}{c}10 \text { months } \\
4\end{array}$ \\
\hline $\begin{array}{c}5 \\
(2 \mathrm{yo}, \mathrm{female})\end{array}$ & Grade 2 & Distention & Positive & Unremarkable & BMO- $\mathrm{t}^{\mathrm{b})}$ & 256 days & $\begin{array}{l}32 \text { months } \\
25\end{array}$ \\
\hline $\begin{array}{c}6 \\
(2 \mathrm{yo}, \text { male })\end{array}$ & Grade 2 & No distention & Positive & Unremarkable & $\mathrm{BMO}-\mathrm{t}^{\mathrm{b})}$ & 406 days & $\begin{array}{c}17 \text { months } \\
5\end{array}$ \\
\hline $\begin{array}{c}7 \\
(2 \mathrm{yo}, \mathrm{male})\end{array}$ & Grade 2 & Distention & Positive & Unremarkable & BMO-t $\mathrm{t}^{\mathrm{b})}$ & c) & $\begin{array}{c}2 \text { months } \\
-\end{array}$ \\
\hline $\begin{array}{c}8 \\
(6 y o, \text { male })\end{array}$ & Grade 2 & No distention & Positive & Unremarkable & BMO-tb) & d) & $\begin{array}{l}- \\
-\end{array}$ \\
\hline
\end{tabular}

a) Lameness is graded according to the American Association of Equine Practitioners scale (0-5). Grade 0 is sound and grade 5 describes the non-weight bearing horse. b) Detection of bone marrow oedema-type (BMO-t) signal in the proximal phalanx. c) Developed comminuted fracture 55 days after the examination. d) Euthanized due to complications following castration surgery 10 days after the examination.

K.K., Osaka, Japan). While the lameness was suspected to be associated with the pathology within the fetlock, there were no radiographic abnormalities (FCR Speedia CS, Fujifilm, Tokyo, Japan) noted in the proximal aspect of P1 in any of the cases. sMRI (Equine Limb Scanner, Hallmarq Veterinary Imaging, Ltd., Guildford, U.K.) revealed BMO-t signal within the trabecular bone of the proximal aspect of P1 (Fig. 1). This characteristic signal pattern comprises intraosseous intermediate-to-high signal intensity surrounded by a hypointense rim on T2*-weighted gradient echo images (echo time [TE], $13 \mathrm{msec}$; repetition time [TR], $68 \mathrm{msec}$; flip angle, $28^{\circ}$ ) and STIR fast spin echo (TE, $22 \mathrm{msec}$; TR, $2,536 \mathrm{msec}$; inversion time [TI], $120 \mathrm{msec}$ ) hyperintensity with corresponding T1-weighted gradient echo (TE, $8 \mathrm{msec}$; TR, $52 \mathrm{msec}$; flip angle, $50^{\circ}$ ) hypointensity. Following the sMRI, all cases were followed up. Six out of 8 cases successfully returned to racing. Case 7 was sent to a resting farm for rehabilitation after sMRI. As the lameness was improved relatively early, the colt commenced hand-walking 2 weeks after the examination. Thereafter, the colt was allowed to graze without restraint in a small paddock. Unfortunately, the colt developed comminuted P1 fracture during paddock grazing 55 days after the examination. Case 8 underwent a histopathological investigation after euthanasia. This case was euthanized 10 days after sMRI due to complications following castration surgery, which was unrelated to the original limb injury. The histopathological investigation of the area showing BMO-t signal revealed multifocal eosinophilic and weak PAS positive material between adipocytes, consistent with oedema (Fig. 2). It was also revealed that the trabecular scaffolding was increased in density.

Unlike condylar fracture of MC3/MT3 [17], it has been believed that sagittal P1 fracture would develop as a result of an acute, one time, biomechanical event [2]. Advances in imaging modalities, such as MRI and scintigraphy have proposed involvement of repetitive stress-injury etiology, characterized by SCB and trabecular bone densification $[6,15]$. This theory is also supported by a recent investigation on warmblood horses using sMRI [7]. MRI allows superior visualization of soft tissues and osseous anatomy, including fluid accumulation within tissues and bones, such as hemorrhage, inflammation, fibrosis, osteonecrosis and oedema [13]. In racehorse practice, the use of sMRI to preclude 'high risk' horses, such as those having pre-fracture pathologies has now been widespread $[12,13]$. Meanwhile, development of P1 fractures in relation to stress-related pathology has been less understood as compared to MC3/MT3. Therefore, the present study aimed to gain further knowledge from cases in racing that underwent sMRI for examination of P1. In addition, a histopathological investigation was conducted in one of the cases to correlate sMRI abnormalities and histological changes in the bone. To the authors' knowledge, histopathologic features of the limb showing the BMO-t signal pattern in $\mathrm{P} 1$ of Thoroughbreds has not been described.

A 0-4 grading system has been proposed for human stress fracture based on different imaging modalities, including radiography and MRI [1]. According to this system, grade 4 is the stage where a fracture line can be detected with any imaging modality. In contrast, the earliest detectable imaging abnormality (grade 1) is hyperintensity on STIR images, derived from increased water content within the bone. In the current study, all cases showed the BMO-t signal pattern in the absence of linear fracture line. Therefore, it was possible that these cases underwent sMRI before advancing to a serious line, which would be clinically significant from the aspect of injury prevention. At the same time, it was also possible that these cases did not have a short incomplete fracture but osseous trauma, as reported by Gold et al. and Lipreri et al. [7, 8]. Previous studies of the distal MC3/MT3 showed that once the damage to the bone was accumulated as a result of intense load, reactively sclerotic change would follow [20]. This is because 


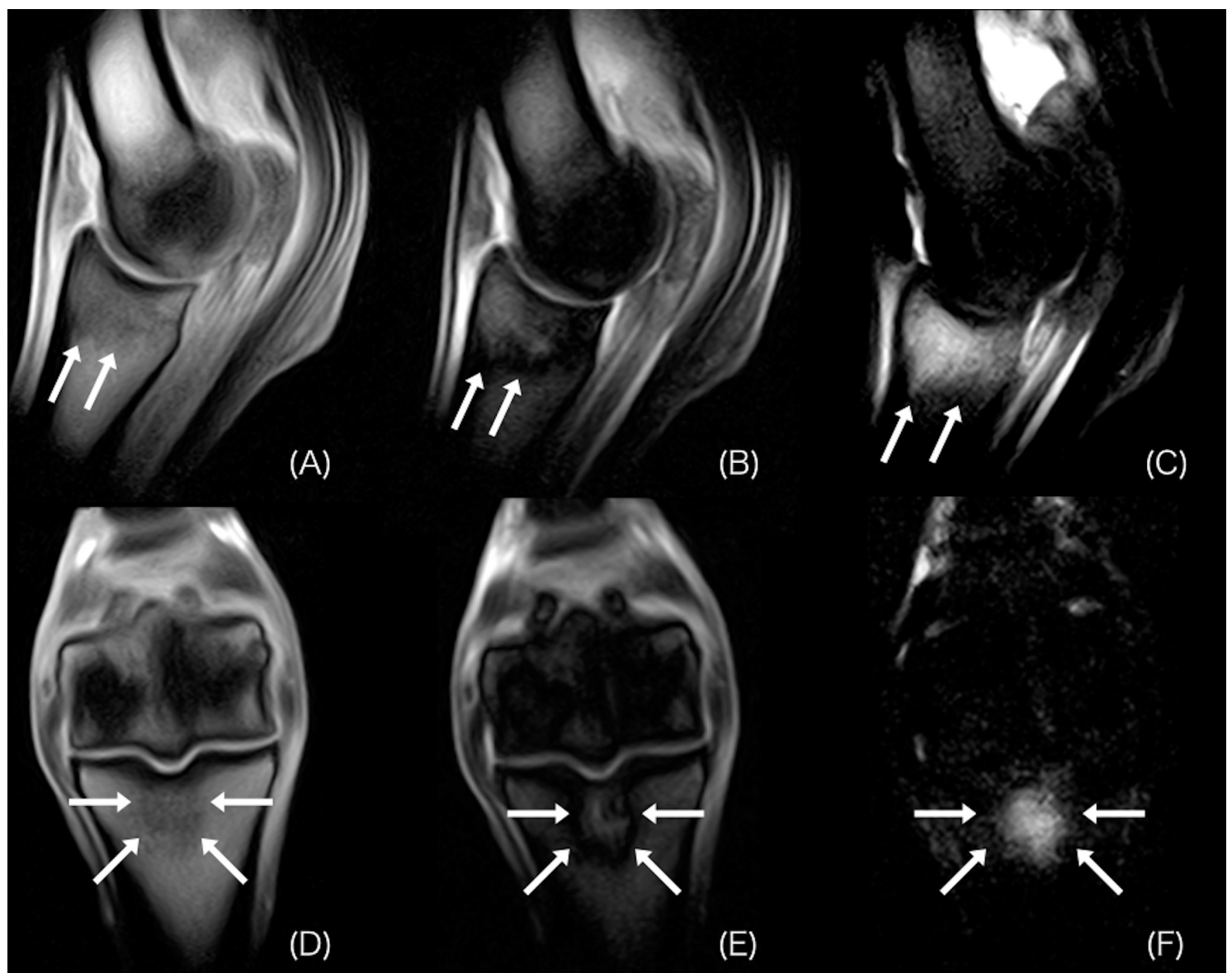

Fig. 1. Representative sagittal (A, B, C) and frontal (D, E, F) T1-weighted, T2*-weighted, and fat-suppressed images of the right proximal phalanx (case 7). An area of low signal intensity within the trabecular bone is visible on T1-weighted images (A, D; arrows), whereas the area has intermediate-to-high signal intensity surrounded by a hypointense rim due to fat-water cancellation artefact on $\mathrm{T} 2 *$-weighted images (B, E; arrows) and markedly high signal intensity on fat-suppressed images (C, F; arrows).

intense load could suppress remodeling of the affected SCB while modeling would increase regional bone volume. Such bone would lose elasticity, resulting in the increase in the risks of fracture [16]. Although this theory has not been clarified in P1, the histopathologic investigation of case 8 showed presence of trabecular bone oedema surrounding adipose tissues with increase in density of trabecular scaffolding. This may indicate the presence of osseous injury within the focal area of decreased elasticity due to SCB modeling. It has been suggested that thickening of the trabeculae of MC3/MT3 could lead to a decrease in biomechanical integrity, and ultimately, increased fracture risk [20]. Noble et al. proposed that maladaptation of P1 SCB to exercise, which was characterized by variance in SCB volumetric mineral density, may provide an alternate explanation to the one-time biomechanical event theory for sagittal fracture of P1 [10]. In the current study, special stains that can directly evaluate modeling and remodeling of the bone were not performed. This would include stains such as tartrate-resistant acid phosphate and alkaline phosphatase. Since these stains require a resin-embedded bone sample without decalcification, this would be a subject for a future study.

In the present study, case 7 developed a comminuted P1 fracture about 2 months from the examination. As the sMRI feature was similar to the other cases, it was suggested that particular care should be taken to the case showing BMO-t signal during the course of rehabilitation to prevent from deterioration of osseous injury. This would include hand-walking to control sudden movement while the paddock grazing is restrained, and planning an internal fixation surgery. It is proposed that indications for the screw fixation of radiographically evident short incomplete sagittal P1 fractures would be fractures that extend more than $15 \mathrm{~mm}$ from the proximal articular surface [18]. One study on the configuration of incomplete proximal fractures of P1, of which fracture lines were shorter than $15 \mathrm{~mm}$, if detected, suggested most fractures were centered dorsally but not bicortical [4]. According to the study, subchondral sclerosis and periosteal new bone formation were evident on computed tomographic images, indicating prodromal fracture pathology. Information is still limited with regard to the indication for the surgery in cases showing BMO-t signal patterns in the absence of radiographically apparent fractures. It is expected that placement of screw may enhance healing through compression along the damaged bone, and minimize the risk of further microcrack propagation. Recently, Lipreri et al. reported that there were no statistically significant differences between the conservative and surgical treatment groups by comparing the outcome of 21 sports horses diagnosed as having osseous trauma within the proximal aspect of P1 [8]. In the current study, majority of the horses returned to racing without surgery. On the other hand, it would be worth noting that one case developed 

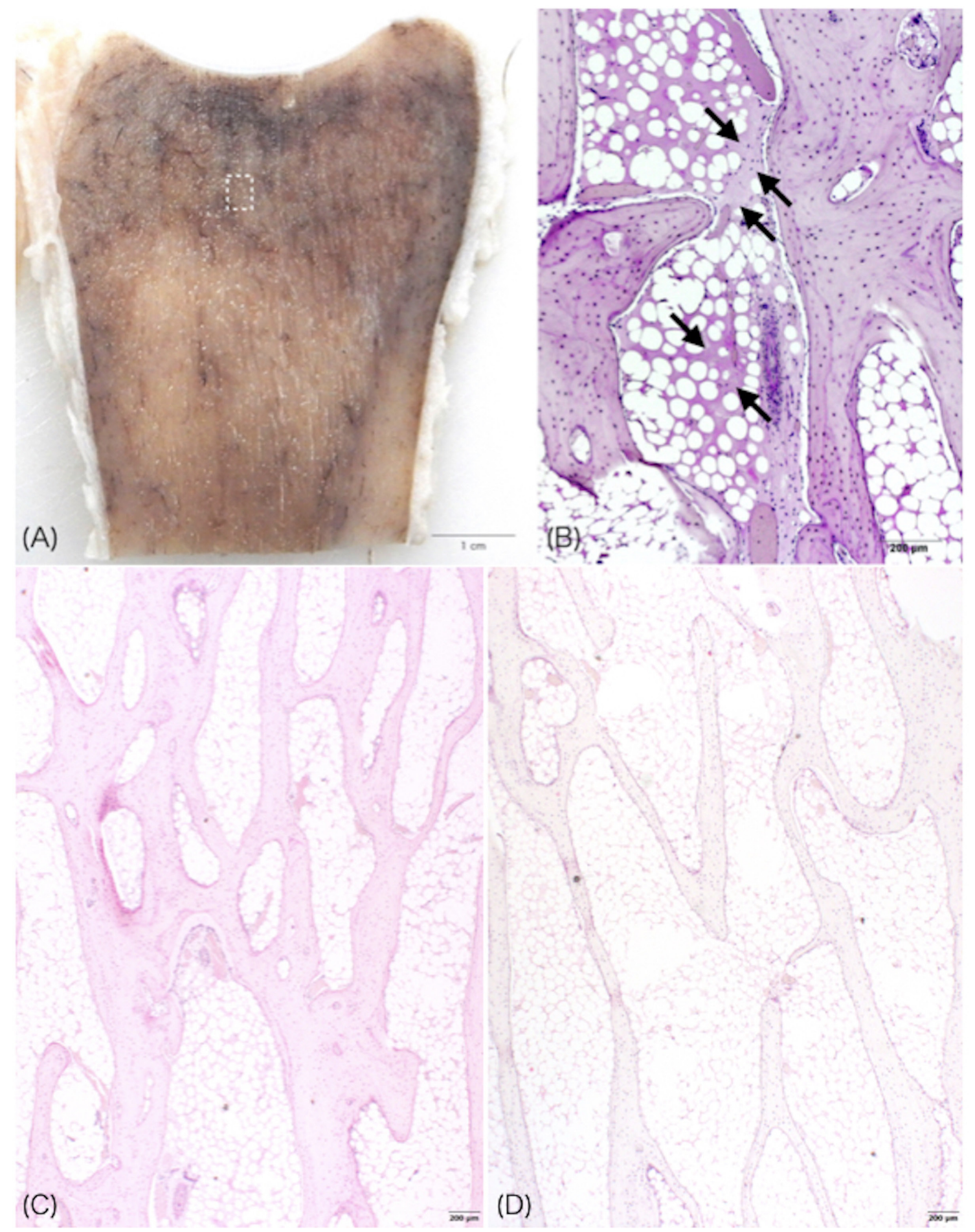

Fig. 2. Gross and histopathological images on the left proximal phalanx from case 8. (A) A sagittal section of the proximal phalanx with the box indicating the area shown on (B) and (C). (B) A sagittal section of the trabecular bone stained with Periodic acid-Schiff (PAS). There is multifocal weak PAS positive material between adipocytes, consistent with oedema (arrows). (C) Hematoxylin and Eosin (H\&S) staining shows an area of increase in density of trabecular scaffolding in comparison to the area in a lateral sagittal section. (D) The H\&E stained lateral sagittal section of the trabecular bone at the same level as (C).

a comminuted P1 fracture during the rehabilitation. Based on inquiry to the trainers of each case, no treatment were conducted other than non-steroidal anti-inflammatory medications when the lameness were still present. Modification of exercise by altering the duration and intensity were considered to be the key component to restore function and prevent progression to fracture. While no cases underwent surgery in the current study, further study on Thoroughbred racehorses would be warranted to determine the 
effective rehabilitation and treatment protocols.

In conclusion, sMRI played an important role in assessing osseous abnormalities that were not radiographically identifiable.

Despite the need for further study, detection of such abnormality based on presence of BMO-t signal pattern within the trabecular bone, and application of appropriate care following the injury may contribute to prevent deterioration of stress-related P1 fractures in Thoroughbred racehorses.

\section{REFERENCES}

1. Arendt, E. A. and Griffiths, H. J. 1997. The use of MR imaging in the assessment and clinical management of stress reactions of bone in highperformance athletes. Clin. Sports Med. 16: 291-306. [Medline] [CrossRef]

2. Bertone, A. L. 2011. Fractures of the distal phalanx. pp. 579-588. In: Adams and Stashak's Lameness in Horses, 6th ed. (Baxter, G. M. ed.), Blackwell Publishing, Ltd., West Sussex.

3. Bonadio, M. B., Filho, A. G. O., Helito, C. P., Stump, X. M. and Demange, M. K. 2017. Bone marrow lesion: image, clinical presentation, and treatment. Magn. Reson. Insights 10: X17703382. [Medline]

4. Brünisholz, H. P., Hagen, R., Fürst, A. E. and Kuemmerle, J. M. 2015. Radiographic and computed tomographic configuration of incomplete proximal fractures of the proximal phalanx in horses not used for racing. Vet. Surg. 44: 809-815. [Medline] [CrossRef]

5. Busoni, V., Heimann, M., Trenteseaux, J., Snaps, F. and Dondelinger, R. F. 2005. Magnetic resonance imaging findings in the equine deep digital flexor tendon and distal sesamoid bone in advanced navicular disease — an ex vivo study. Vet. Radiol. Ultrasound 46: 279-286. [Medline] [CrossRef]

6. Dyson, S., Nagy, A. and Murray, R. 2011. Clinical and diagnostic imaging findings in horses with subchondral bone trauma of the sagittal groove of the proximal phalanx. Vet. Radiol. Ultrasound 52: 596-604. [Medline] [CrossRef]

7. Gold, S. J., Werpy, N. M. and Gutierrez-Nibeyro, S. D. 2017. Injuries of the sagittal groove of the proximal phalanx in warmblood horses detected with low-field mag- netic resonance imaging: 19 cases (2007-2016). Vet. Radiol. Ultrasound 58: 344-353. [Medline] [CrossRef]

8. Lipreri, G., Bladon, B. M., Giorio, M. E. and Singer, E. R. 2018. Conservative versus surgical treatment of 21 sports horses with osseous trauma in the proximal phalangeal sagittal groove diagnosed by low-field MRI. Vet. Surg. 47: 908-915. [Medline] [CrossRef]

9. Murray, R. C., Blunden, T. S., Schramme, M. C. and Dyson, S. J. 2006. How does magnetic resonance imaging represent histologic findings in the equine digit? Vet. Radiol. Ultrasound 47: 17-31. [Medline] [CrossRef]

10. Noble, P., Singer, E. R. and Jeffery, N. S. 2016. Does subchondral bone of the equine proximal phalanx adapt to race training? J. Anat. 229: 104-113. [Medline] [CrossRef]

11. Peterfy, C. G. 2004. MRI of the wrist in early rheumatoid arthritis. Ann. Rheum. Dis. 63: 473-477. [Medline] [CrossRef]

12. Powell, S. E. 2012. Low-field standing magnetic resonance imaging findings of the metacarpo/metatarsophalangeal joint of racing Thoroughbreds with lameness localised to the region: a retrospective study of 131 horses. Equine Vet. J. 44: 169-177. [Medline] [CrossRef]

13. Powell, S. E. 2015. Magnetic resonance imaging of the fetlock joint. pp. 823-831. In: Robinson's Current Therapy in Equine Medicine (Sprayberry, K. A. and Robinson, N. E. eds.), Elsevier Saunders, St. Louis.

14. Powell, S. E., Ramzan, P. H. L., Head, M. J., Shepherd, M. C., Baldwin, G. I. and Steven, W. N. 2010. Standing magnetic resonance imaging detection of bone marrow oedema-type signal pattern associated with subcarpal pain in 8 racehorses: a prospective study. Equine Vet. J. 42: 10-17. [Medline] [CrossRef]

15. Ramzan, P. H. L. and Powell, S. E. 2010. Clinical and imaging features of suspected prodromal fracture of the proximal phalanx in three Thoroughbred racehorses. Equine Vet. J. 42: 164-169. [Medline] [CrossRef]

16. Riggs, C. M. 2006. Osteochondral injury and joint disease in the athletic horse. Equine Vet. Educ. 18: 100-112. [CrossRef]

17. Riggs, C. M., Whitehouse, G. H. and Boyde, A. 1999. Pathology of the distal condyles of the third metacarpal and third metatarsal bones of the horse. Equine Vet. J. 31: 140-148. [Medline] [CrossRef]

18. Ruggles, A. J. 2010. Fractures of the proximal phalanx. pp. 388-390. In: Lameness in the Horse (Ross, M. and Dyson, S. eds.), Elsevier Saunders, St. Louis.

19. Werpy, N. 2009. Diagnosis of middle phalanx bone marrow lesions in horses using magnetic resonance imaging and identification of phase effect cancellation for proper image interpretation. Equine Vet. Educ. 21: 125-130. [CrossRef]

20. Whitton, R. C., Trope, G. D., Ghasem-Zadeh, A., Anderson, G. A., Parkin, T. D. H., Mackie, E. J. and Seeman, E. 2010. Third metacarpal condylar fatigue fractures in equine athletes occur within previously modelled subchondral bone. Bone 47: 826-831. [Medline] [CrossRef] 